\title{
Evaluation of Bonwill triangle using cone beam computerized tomography in Korean
}

\author{
Hyun-Jun Kong, Sang-Chun Oh* \\ Department of Prosthodontics, College of Dentistry, Wonkwang University, Iksan, Republic of Korea
}

Purpose: The aim of this study was to evaluate the Bonwill triangle of Korean using the cone beam computerized tomography (Cone-beam CT). Materials and Methods: 120 Koreans (60 males and 60 females) who visited Daejeon Dental College Hospital of Wonkwang University and who underwent the Cone-beam CT were selected. The Cone-beam CT images were analysed with Invivo 5.1 (Anatomage, San Jose, USA). After reorientation of axis, the intercondylar distance was measured by clicking both middle points of condyle. And the condyle-incisor distance was measured by clicking the middle point of condyle and contact point of the mandibular central incisor's incisal edge. The collected data were analysed using the SPSS Version 23.0 (IBM Inc., Armonk, USA) and statistical significance was verified by gender using independent t-test. Results: The mean intercondylar distance of Korean was 105.9 mm, and the male $(108.3 \mathrm{~mm})$ was statistically significantly larger than the female $(103.4 \mathrm{~mm})$. The mean condyle-incisor distance of Korean was $105.2 \mathrm{~mm}$, and the male $(108.1 \mathrm{~mm})$ was statistically significantly larger than the female (102.3 mm). Conclusion: The mean intercondylar distance of Korean in this study was $105.9 \mathrm{~mm}$ that was smaller than well-known $110 \mathrm{~mm}$ of Caucasian and the male was statistically significantly larger than the female. Within the limitations of this study, it would be necessary to use the articulator which can adjust the intercondylar distance according to the individual for prosthodontic treatment of Korean. (J Dent Rehabil Appl Sci 2018;34(2):97-103)

Key words: Bonwill triangle; articulator; intercondylar distance; cone-beam CT

\section{서론}

본윌 삼각(Bonwill triangle)은 하악 중절치 절치연의 접촉점과 양쪽 과두를 연결하는 선에 의해서 경계되어지 는 4인치의 이등변 삼각형으로 1858 년에 Bonwill의 해 부학적 교합기에 처음 소개되었다. ${ }^{1}$ Bonwill의 교합기는 평균치 교합기이며, 과두간 거리 및 과두-절치간 거리를 $100 \mathrm{~mm}$ 로 고정하였다. ${ }^{2}$

이중 과두간 거리는 교두융선과 구의 방향 및 전치부 설면 형태에 영향을 미친다. 과두간 거리가 증가함에 따 라, 과두와 치열궁의 치아 사이의 거리를 증가시켜 내외

${ }^{*}$ Correspondence to: Sang-Chun Oh

Professor, Department of Prosthodontics, College of Dentistry, Wonkwang University, 77 Doonsan-ro, Seo-gu, Daejeon, 35233, Republic of Korea Tel: +82-42-366-1100, Fax: +82-42-366-1115, E-mail: scoh@wku.ac.kr Received: February 6, 2018/Last Revision: March 3, 2018/Accepted: March 5, 2018
측방로 사이각을 더 크게 하지만 회전 과두와 치열과의 거리 증가에 비해 치아가 상대적으로 정중시상면에 가깝 게 위치되어 이의 영향을 많이 받기 때문에 내외측방로 사이의 각도를 감소시키는 경향이 발생하게 된다. 또한 과두간 거리가 커질수록 상악전치의 설면 함몰부는 커지 고 과두간 거리가 작아질수록 상악전치의 설면 함몰부는 작아진다.

과두-절치간 거리는 교두융선과 구의 방향에 영향을 미치며, 하악 회전축(회전과두)으로부터 치아가 멀리 떨 어져 있을수록 상악과 하악에 있어 외측방로와 내측방로 가 이루는 사이각이 커진다. ${ }^{3}$

CopyrightC 2018 The Korean Academy of Stomatognathic Function and Occlusion. (c) It is identical to Creative Commons Non-Commercial License. 
그간 과두간 거리에 관한 연구가 진행되어 왔는데, $\mathrm{Keshvad}^{4}$ 는 백인을 대상으로 평균 과두간 거리를 110.54 $\mathrm{mm}$ 라고 보고하였고, Tradowsy ${ }^{5}$ 는 미국인을 대상으로 남성 $108 \mathrm{~mm}$, 여성 $102 \mathrm{~mm}$ 로 보고하였으며, Lazic 등 ${ }^{6}$ 은 크로아티아인을 대상으로 남성 $130.2 \mathrm{~mm}$, 여성 123.5 $\mathrm{mm}$ 로 보고하였다.

그러나 서양인과 한국인의 치아 및 악궁의 크기와 형 태, 연조직 외형 등에는 차이가 있으므로, 과두간 거리 및 과두-절치간 거리 또한 인종 간에 차이가 있을 것으로 추 측할 수 있다. ${ }^{7-10}$

그러므로 본 연구에서는 최근에 널리 사용되고 있는 콘빔형 전산화단층영상(Cone-beam computerized tomography)을 이용하여 한국인의 과두간 거리 및 과두절치간 거리를 측정하였으며 이를 성별에 따라 비교 분석 하여 한국인의 본윌 삼각을 평가하고자 하였다.

\section{연구 재료 및 방법}

\section{1. 연구 대상}

원광대학교 대전치과병원에서 Cone-beam CT (PaXZenith 3D; Vatech Korea Co., Ltd., Seoul, Korea)를 촬 영한 환자 중에서, 본 연구의 기준에 부합되는 120 명(남성 60 명, 여성 60 명)을 대상으로 개인의 과두간 거리, 과두절치간 거리를 측정하였다. 본 연구는 원광대학교 대전치 과병원 IRB심사(IRB No. W1721/001-001)를 거쳐 진행 되었다. 연구대상 선정의 기준은 Ferrario 등 ${ }^{11,12}$ 의 연구에 서 사용한 기준을 참고하여 다음과 같이 설정하였다.

포함기준:

(1) 한국인

(2) 제 3 대구치를 제외한 치아 결손이 없는 영구치열

(3) Angle 분류 class 1

제외기준:

(1) 교정 치료 및 악교정 수술 기왕력

(2) 악관절장애로 인한 치료 및 하악 과두를 포함하는 외과적 수술 기왕력

(3) 상악과 하악의 중절치에 교두를 피개하는 수복물이 있는 경우

(4) 그 밖의 이유로 계측 포인트가 Cone-beam CT 상 에 매우 불량하여 계측이 힘든 경우

연구 대상에 포함된 120 명의 성별, 연령별 분포는 다음 과 같다(Table 1).

\section{2. 연구 방법}

1) 악궁의 디지털화

Cone-beam CT로부터 얻어진 이미지를 digital imaging and communications in medicine (DICOM) format 으로 추출하였다. Cone-beam CT scan을 분석하기 위 해 Invivo 5.1 (Anatomage, San Jose, USA)을 사용하였 다. 축의 방향설정(reorientation of axis)은 Bayome ${ }^{13}$ 등 의 연구에서 사용한 방법을 참고하였다. 먼저 관상영상 (coronal view)에서 X축은 좌측 및 우측 Orbitale를 지 나는 수평선으로 설정하였다(Fig. 1A). 다음으로 시상영 상(sagittal view)에서 $\mathrm{Y}$ 축은 Nasion과 Anterior Nasal Spine (ANS)를 지나는 수직선으로 설정하였다(Fig. 1B). 마지막으로 축영상(axial view)에서 $\mathrm{Y}$ 축은 ANS와 Posterior Nasal Spine (PNS)을 지나는 수직선으로 설정하였 다(Fig. 1C).

\section{2) 계측 기준}

과두간 거리와 과두-절치간 거리를 계측하기 위해 계 측점을 설정하였다(Fig. 2).

과두간 거리의 계측을 위해 관상영상에서 영상조절 (view control)을 경조직(bone)으로 설정하였다. 이후 5 $\mathrm{mm}$ 간격으로 클리핑(clipping)하면서, 각 과두의 최대 외 연이 보이는 상을 선택한 후, Nagi 등 ${ }^{14}$ 의 연구를 참고하 여 각 과두의 최대 외연과 내연의 중심점을 찾아, 각 과두 의 중심점을 클릭하여 과두간 거리를 측정하였다(Fig. 3).

과두-절치간 거리는 각 과두 중심점에서 하악 양 중절 치 절단연의 접촉점까지의 거리를 의미하는 것이다. 이를 측정하기 위해 관상영상에서 과두 중심점을 클릭하고 영 상조절을 치아(teeth)로 변환한 후, 하악 양 중절치 절단 연의 접촉점을 클릭하여 각 과두-절치간 거리를 계측하 였다(Fig. 4).

Table 1. Distribution of patients by age and gender

\begin{tabular}{cccc}
\hline Age & Male & Female & Total \\
\hline $10-19$ & 15 & 13 & 28 \\
$20-29$ & 30 & 27 & 57 \\
$30-39$ & 6 & 9 & 15 \\
$40-49$ & 3 & 6 & 9 \\
$>50$ & 6 & 5 & 11 \\
Total & 60 & 60 & 120 \\
\hline
\end{tabular}



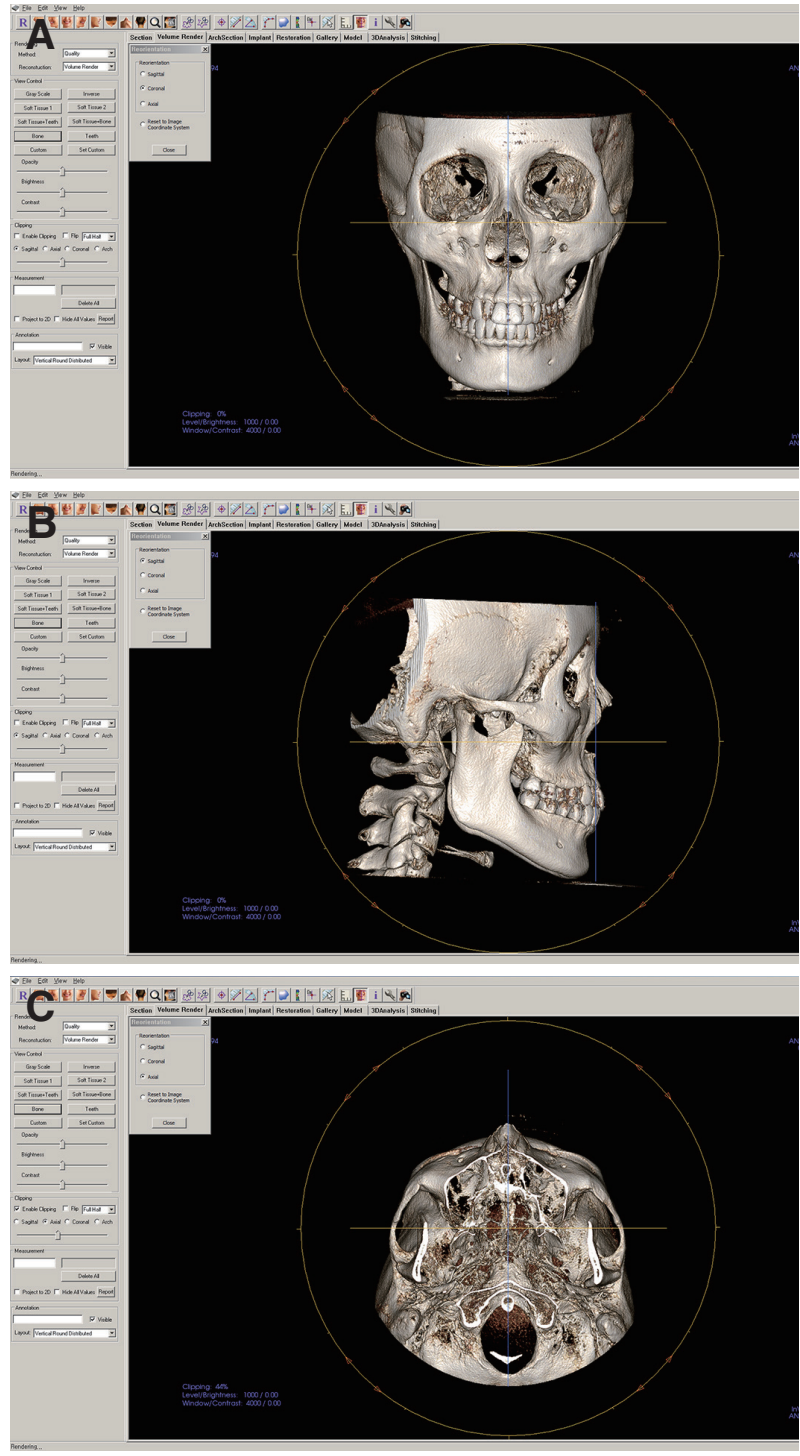

Fig. 1. Reorientation of axis. (A) Coronal viewm, (B) Sagittal view, (C) Axial view.

A

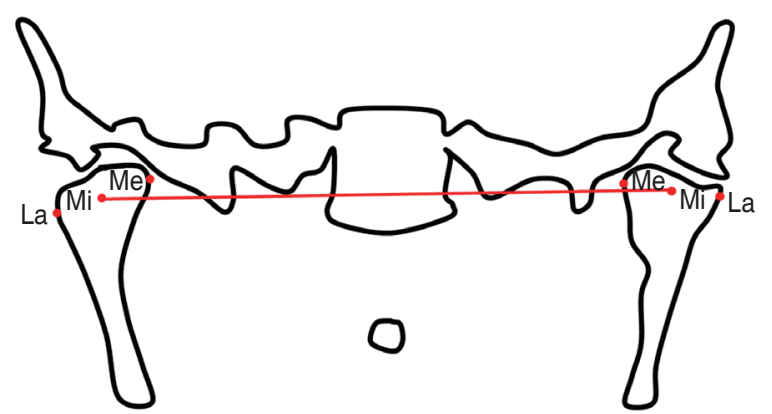

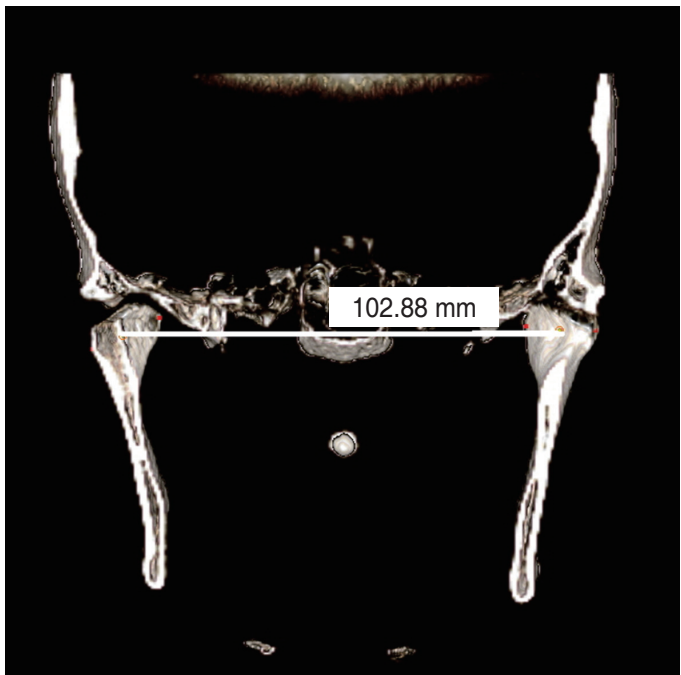

Fig. 3. Intercondylar distance.

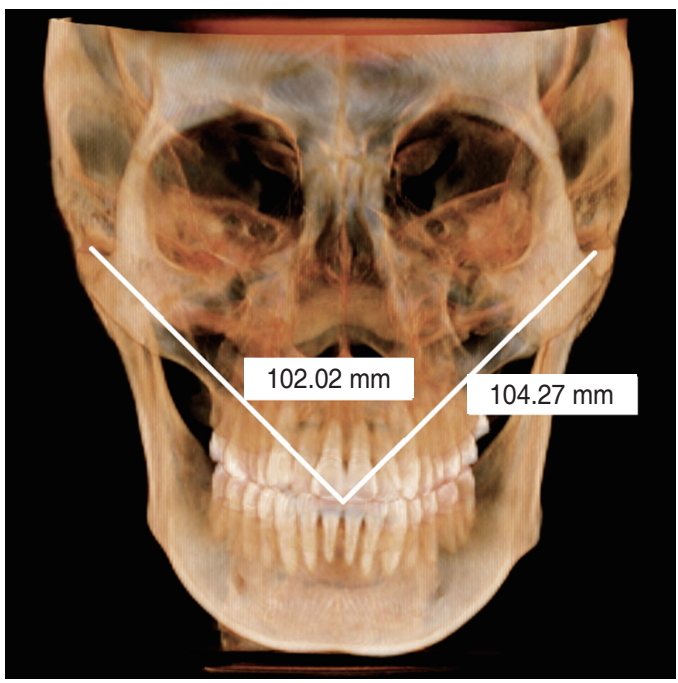

Fig. 4. Condyle-incisor distance.

B

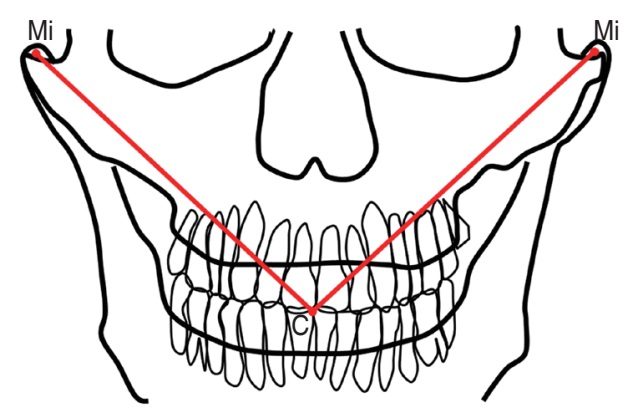

Fig. 2. Schematic diagram of intercondylar distance $(A)$ and condyle-incisor distance (B). La: lateral-most point of condyle; Me: medial-most point of condyle; Mi: middle point of condyle; $\mathrm{C}$ : contact point of the mandibular central incisor's incisal edge. 


\section{3) 통계 분석}

과두간 거리와 과두-절치간 거리의 성별 차이의 통계 적 유의성을 검증하기 위하여 independent t-test를 시 행하였다. 통계처리에는 SPSS Version 23.0 (IBM Inc., Armonk, USA)을 이용하였다.

\section{결과}

한국인의 평균 과두간 거리는 $105.9 \mathrm{~mm}$ 였으며, 남성 $(108.3 \mathrm{~mm})$ 이 여성 $(103.4 \mathrm{~mm})$ 에 비해 통계학적으로 유 의하게 크게 나타났다(Table 2).

한국인의 평균 좌측 과두-절치간 거리는 $105.5 \mathrm{~mm}$ 였 으며, 남성 $(108.6 \mathrm{~mm})$ 이 여성 $(102.4 \mathrm{~mm})$ 에 비해 통계학 적으로 유의하게 크게 나타났다.

한국인의 평균 우측 과두-절치간 거리는 $104.9 \mathrm{~mm}$ 였 으며, 남성 $(107.6 \mathrm{~mm})$ 이 여성 $(102.2 \mathrm{~mm})$ 에 비해 통계학 적으로 유의하게 크게 나타났다.

한국인의 평균 과두-절치간 거리는 $105.2 \mathrm{~mm}$ 였으며, 남성 $(108.1 \mathrm{~mm})$ 이 여성 $(102.3 \mathrm{~mm})$ 에 비해 통계학적으 로 유의하게 크게 나타났다(Table 3).

한국인의 평균 좌측 과두-절치간 거리 $(105.5 \mathrm{~mm})$ 와 우 측 과두-절치간 거리 $(104.9 \mathrm{~mm})$ 는 통계학적으로 유의한 차이가 없었다(Table 4).

\section{고찰}

교합기는 측두하악관절과 하악의 움직임을 재현할 수 있는 기계적 장치로서 악골운동을 구강 외에서 재현함 으로써 인체의 기능에 조화된 보철물을 제작하기 위하여 사용한다. ${ }^{15}$ 하악골의 모든 운동은 일정한 한계 내에서 일어나며, 교합기가 이러한 한계운동을 더 유사하게 재 현할수록 정확한 교합과 하악운동을 분석할 수 있으며 구강 내에서 장애를 일으키지 않는 좋은 보철물을 제작 할 수 있게 된다.

교합기의 설정된 과두간 거리가 환자의 그것에 비하여 크거나 작을 경우, 교두의 움직임을 재현하는 데에 미세 한 오차가 생길 수 있다. 교합기의 과두간 거리가 하악보 다 작을 경우 교합기 운동의 축이 환자의 구강운동에 비 해 미세하게 근심으로 위치하게 되며, 하악보다 클 경우 환자의 구강운동에 비해 원심에 있게 된다. ${ }^{16}$

고정성 보철물 제작을 위한 반조절성 교합기의 사용은 치료기간 중에 임상적인 조절을 최소로 하는 최대한의 진단 정보를 제공하며, 인체의 해부학적 구조와 거의 같 은 크기이기 때문에 오차가 최소이다. 현재 한국에서 사 용되는 많은 반조절성 교합기의 과두간 거리는 $110 \mathrm{~mm}$ 로 고정되어 있다. KaVo PROTARevo (Kavo Dental, Charlotte, USA)와, Hanau H2 (Whipmix Corporation,

Table 2. Independent t-test for differences of intercondylar distance between male and female

\begin{tabular}{|c|c|c|c|c|c|c|}
\hline & \multicolumn{2}{|c|}{ Male } & \multicolumn{2}{|c|}{ Female } & \multirow{2}{*}{$\mathrm{t}$} & \multirow{2}{*}{$P$} \\
\hline & Mean & SD & Mean & $\mathrm{SD}$ & & \\
\hline Intercondylar distance & 108.3 & 4.84 & 103.4 & 4.88 & 5.59 & $.000^{*}$ \\
\hline
\end{tabular}

Table 3. Independent t-test for differences of condyle-incisor distance between male and female

\begin{tabular}{lllllll}
\hline & \multicolumn{2}{c}{ Male } & \multicolumn{2}{c}{ Female } & t & P \\
& Mean & SD & Mean & SD & & \\
\hline Lt. condyle - incisor distance & 108.6 & 4.65 & 102.4 & 4.22 & 7.65 & $.000^{*}$ \\
Rt. condyle - incisor distance & 107.6 & 4.77 & 102.2 & 4.37 & 6.51 & $.000^{*}$ \\
Condyle - incisor distance & 108.1 & 4.50 & 102.3 & 4.00 & 7.49 & $.000^{*}$ \\
\hline
\end{tabular}

$*: P<.01$

Table 4. Independent t-test for differences of condyle-incisor distance between left and right

\begin{tabular}{|c|c|c|c|c|c|c|}
\hline & \multicolumn{2}{|c|}{ Left } & \multicolumn{2}{|c|}{ Right } & \multirow[b]{2}{*}{$\mathrm{t}$} & \multirow{2}{*}{$P$} \\
\hline & Mean & $\mathrm{SD}$ & Mean & $\mathrm{SD}$ & & \\
\hline Condyle-incisor distance & 105.5 & 5.41 & 104.9 & 5.31 & 0.89 & $.376^{*}$ \\
\hline
\end{tabular}


Louisville, USA)는 $110 \mathrm{~mm}$ 로 고정되어 있으며, Whip Mix articulator (Whipmix Corporation, Louisville, $\mathrm{USA}$ 는 $96 \mathrm{~mm}, 110 \mathrm{~mm}, 124 \mathrm{~mm}$ 로 조절이 가능하다. 그러나 이렇게 서양인을 대상으로 제시된 $110 \mathrm{~mm}$ 의 과 두간 거리를 한국인에 적용 시 치아 및 악궁의 크기와 형 태의 차이로 인한 오차를 예상해 볼 수 있다. 따라서 한 국인에게 적합한 교합기의 개발을 위해서는 한국인의 악 구강계 관련 치수를 분류 및 정리하는 것이 필요하다.

Cone-beam CT는 근래에 널리 사용되고 있으며, 악구 강계 관련 치수를 3 차원적으로 신속하고 정확하게 분석 할 수 있는 유용한 영상진단 수단이다. 따라서 본 연구에 서도 Cone-beam CT를 사용하여 지금까지 보고된 적이 없는 한국인의 과두간 거리와 과두-절치간 거리를 분석 하였다.

한국인의 과두간 거리를 분석하였을 때 한국인의 평균 과두간 거리는 $105.9 \mathrm{~mm}$ 로 $\mathrm{Keshvad}^{4}$ 에 의해 보고된 서 양인의 평균 과두간 거리인 $110.54 \mathrm{~mm}$ 에 비해 작은 수 치를 나타냈다. 이러한 결과는 한국인과 서양인의 과두 간 거리에는 차이가 있으며, 한국인의 구강재건을 위한 반조절성 교합기 사용에 있어서 표준화된 $110 \mathrm{~mm}$ 의 적 용을 재고할 필요성을 의미한다.

평균 과두간 거리의 성별에 따른 차이를 보면, 남성 $108.3 \mathrm{~mm}$ 여성 $103.4 \mathrm{~mm}$ 로 남성의 과두간 거리가 통계 학적으로 유의하게 더 큰 것으로 나타났다. 과두간 거리 에 관한 Tradowsy ${ }^{5}$ 와 Lazic 등 ${ }^{6}$ 의 연구에서도 남성이 여 성보다 큰 거리를 보였으며, 이는 한국인의 스피만곡 반 경의 성별에 따른 차이를 보고한 $\mathrm{Oh}$ 등 $^{17}$ 의 연구결과와 유사하다.

또한 양측 과두에서의 절치간 거리를 조사한 결과 남 성의 평균 좌측 과두-절치간 거리는 $108.6 \mathrm{~mm}$ 우측 과 두-절치간 거리는 $107.6 \mathrm{~mm}$ 로 통계학적으로 유의할만 한 차이는 없었다. 여성의 평균 좌측 과두-절치간 거리는 $102.4 \mathrm{~mm}$ 우측 과두-절치간 거리는 $102.2 \mathrm{~mm}$ 로 통계학 적으로 유의한 차이는 없었다. Lundström ${ }^{18}$ 과 Williamson과 Simmons ${ }^{19}$ 는 치열과 두개골의 성장발육이 대칭적 으로 이루어지기는 어렵다고 보고하였는데, 본 연구에서 나타난 개인의 좌우 과두-절치간 거리의 차이가 이러한 비대칭적인 성장에 기인한 것이라고 생각할 수 있다.

본 연구에서 측정된 한국인의 평균 과두간 거리는 $105.9 \mathrm{~mm}$ 로 $110 \mathrm{~mm}$ 보다 작은 값을 보였다. 또한 남성 이 여성에 비해 통계학적으로 유의하게 크게 나타난 것 을 고려했을 때 한국인에게 특정 수치를 일괄적으로 적
용하는 것은 바람직하지 않다고 판단되었다. 과두간 거 리는 교합면 형태에 영향을 미치는 요소이므로 한국인의 보철적 수복에 있어서 절대적인 수치가 적용된 반조절성 교합기의 사용보다는, 각 개인에 맞는 과두간 거리로 조 절 가능한 교합기의 사용이 필요할 것이다.

향후 한국인에게 적합한 반조절성 교합기의 제작을 위 하여, 한국인의 과두 경사로와 전방 경사로 등에 대한 추 가적인 연구가 필요할 것으로 사료된다.

\section{결론}

한국인의 본윌 삼각을 평가하기 위해 120 명의 Conebeam CT 영상으로 과두간 거리와 과두-절치간 거리를 분석한 결과, 다음과 같은 결론을 내릴 수 있었다.

1. 한국인의 과두간 거리는 $105.9 \mathrm{~mm}$ 였으며, 과두-절 치간 거리는 $105.2 \mathrm{~mm}$ 였다.

2. 성별에 따른 과두간 거리는 남성 $(108.3 \mathrm{~mm})$ 이 여성 $(103.4 \mathrm{~mm})$ 에 비해 통계학적으로 유의하게 크게 나 타났다.

3. 성별에 따른 과두-절치간 거리는 남성 $(108.1 \mathrm{~mm})$ 이 여성 $(102.3 \mathrm{~mm})$ 에 비해 통계학적으로 유의하게 크 게 나타났다.

본 연구에서 측정된 한국인의 평균 과두간 거리는 $105.9 \mathrm{~mm}$ 로 서양인을 기준으로 제시된 $110 \mathrm{~mm}$ 에 비해 작았다. 이것은 한국인의 구강재건에 있어서 표준화된 과두간 거리의 적용을 다시 고려해야 할 필요성을 의미 한다.

\section{ORCID}

Hyun-Jun Kong https://orcid.org/0000-0001-9331-3572

Sang-Chun Oh http://orcid.org/0000-0001-5496-126X

\section{References}

1. The Academy of Prosthodontics. The glossary of prosthodontics terms. J Prosthet Dent 2005;94:1092.

2. Jain AR. Articulators through the years revisited: from 1700 to 1900-part I. World J Dent 2015;6:2225.

3. Lee SH. Fixed prosthodontics. 2nd ed. Seoul; 
Jisung Publishing Co.; 2007. p. 101-2.

4. Keshvad A, Winstanley RB, Hooshmand T. Intercondylar width as a guide to setting up complete denture teeth. J Oral Rehabil 2000;27:217-26.

5. Tradowsy M. Sex difference in intercondylar distance. J Prosthet Dent 1990;63:301-2.

6. Lazić B, Teparcević B, Keros J, Komar D, Stanicić T, Azinović Z. Intercondylar distances of the human temporomandibular joints. Coll Antropol 2006;30: $37-41$.

7. Lee KY, Lee DJ. A comparative study of teeth and dental arch of Korean and Caucasian. Oral Biol Res 1993;71:1-15.

8. Song WC, Yun KH, Koh KS. Facial flatness of Korean: using facial depth. Korean J Anat 2003;36: 499-506.

9. Kook YA, Nojima K, Moon HB, McLaughlin RP, Sinclair PM. Comparison of arch forms between Korean and North American white populations. Am J Orthod Dentofacial Orthop 2004;126:680-6.

10. Hwang HS, Kim WS, McNamara JA Jr. Ethnic differences in the soft tissue profile of Korean and European-American adults with normal occlusions and well-balanced faces. Angle Orthod 2002;72:7280 .

11. Ferrario VF, Sforza C, Miani A Jr, Colombo A, Tartaglia G. Mathematical definition of the curve of Spee in permanent healthy dentitions in man. Arch
Oral Biol 1992;37:691-4.

12. Ferrario VF, Sforza C, Miani A Jr, Tartaglia G. Mathematical definition of the shape of dental arches in human permanent healthy dentitions. Eur J Orthod 1994;16:287-94.

13. Bayome M, Park JH, Kook YA. New three-dimensional cephalometric analyses among adults with a skeletal Class I pattern and normal occlusion. Korean J Orthod 2013;43:62-73.

14. Naji P, Alsufyani NA, Lagravére MO. Reliability of anatomic structures as landmarks in three-dimensional cephalometric analysis using CBCT. Angle Orthod 2014;84:762-72.

15. Beck HO. Choosing the articulator. J Am Dent Assoc 1962;64:468-75.

16. Hobo S, Shillingburg HT Jr, Whitsett LD. Articulator selection for restorative dentistry. J Prosthet Dent 1976;36:35-43.

17. Oh SC, Kim SG, Kim YJ. An evaluation of curve of Spee using cone beam computerized tomography in Korea. J Dent Rehabil Appl Sci 2014;30:93101.

18. Lundström A. Some asymmertries of the dental arches, Jaws, and skull, and their etiological significance. Am J Orthod 1961;47:81-106.

19. Williamson EH, Simmons MD. Mandibular asymmetry and its relation to pain dysfunction. Am J Orthod 1979;76:612-7. 


\section{콘빔형 전산화단층영상을 이용한 한국인의 본윌 삼각에 대한 평가}

\section{공현준, 오상천*}

원광대학교 치과대학 치과보철학교실

목적: 본 연구의 목적은 콘빔형 전산화단층영상(cone-beam computerized tomography)을 이용하여 한국인의 본윌 삼각 을 평가함으로써 그간 서양인을 기준으로 제시된 본윌 삼각 관련 수치와 비교하기 위함이다.

연구 재료 및 방법: 원광대학교 치과대학 대전치과병원에 내원하여 Cone-beam CT를 촬영한 환자 중, 본 연구의 기준에 적합한 한국인 120명(남성 60명, 여성 60명)이 선택되었으며 Invivo 5.1 (Anatomage, San Jose, USA)가 Cone-beam CT scan을 분석하기 위해 사용되었다. 축의 방향설정을 시행한 후, 과두간 거리는 각 과두의 중심점을 지정하여 측정하였 으며, 과두-절치간 거리는 과두 중심점과 하악 양 중절치 절단연의 접촉점을 지정하여 측정하였다. 수집된 자료는 SPSS Version 23.0 (IBM Inc., Armonk, USA)을 이용하여 분석하였고, independent t-test를 이용하여 성별에 따른 통계적 유 의성을 검증하였다.

결과: 한국인의 평균 과두간 거리는 $105.9 \mathrm{~mm}$ 였으며, 남성 $(108.3 \mathrm{~mm})$ 이 여성 $(103.4 \mathrm{~mm})$ 에 비해 통계학적으로 유의하 게 크게 나타났다. 한국인의 평균 과두-절치간 거리는 $105.2 \mathrm{~mm}$ 였으며, 남성 $(108.1 \mathrm{~mm})$ 이 여성 $(102.3 \mathrm{~mm})$ 에 비해 통계 학적으로 유의하게 크게 나타났다.

결론: 본 연구에서 측정된 한국인의 과두간 거리는 $105.9 \mathrm{~mm}$ 로 서양인을 대상으로 제시된 $110 \mathrm{~mm}$ 에 비해 작은 값을 보 였으며, 남성이 여성에 비해 통계학적으로 유의하게 크게 나타났다. 본 제한된 연구 결과를 근거로 한국인의 보철적 수복 시 과두간 거리를 좀 더 개인에 맞게 조절할 수 있는 교합기 사용이 필요하다고 사료된다.

(구강회복응용과학지 2018;34(2):97-103)

주요어: 본윌 삼각; 교합기; 과두간 거리; 콘빔형 전산화단층영상

*교신저자: 오상천

(35233) 대전광역시 서구 둔산로 77 원광대학교 대전치과병원 치과보철과

Tel: 042-366-1100 | Fax: 042-366-1115 | E-mail: scoh@wku. ac.kr

접수일: 2018년 2월 6일 | 수정일: 2018년 3월 3일 | 채택일: 2018년 3월 5일 